\title{
Teleological reasoning, not acceptance of evolution, impacts students' ability to learn natural selection
}

\author{
M. Elizabeth Barnes ${ }^{1}$ (D) E. Margaret Evans ${ }^{2 *}$, Ashley Hazel ${ }^{3}$, Sara E. Brownell ${ }^{1}$ and Randolph M. Nesse
}

\begin{abstract}
Background: How acceptance of evolution relates to understanding of evolution remains controversial despite decades of research. It even remains unclear whether cultural/attitudinal factors or cognitive factors have a greater impact on student ability to learn evolutionary biology. This study examined the influence of cultural/attitudinal factors (religiosity, acceptance of evolution, and parents' attitudes towards evolution) and cognitive factors (teleological reasoning and prior understanding of natural selection) on students' learning of natural selection over a semesterlong undergraduate course in evolutionary medicine.

Method: Pre-post course surveys measured cognitive factors, including teleological reasoning and prior understanding of natural selection, and also cultural/attitudinal factors, including acceptance of evolution, parent attitudes towards evolution, and religiosity. We analyzed how these measures influenced increased understanding of natural selection over the semester.

Results: After controlling for other related variables, parent attitude towards evolution and religiosity predicted students' acceptance of evolution, but did not predict students' learning gains of natural selection over the semester. Conversely, lower levels of teleological reasoning predicted learning gains in understanding natural selection over the course, but did not predict students' acceptance of evolution.
\end{abstract}

Conclusions: Acceptance of evolution did not predict students' ability to learn natural selection over a semester in an evolutionary medicine course. However, teleological reasoning did impact students' ability to learn natural selection.

Keywords: Evolution, Natural selection, Teleology, Teleological, Acceptance

\section{Introduction and background}

Recent research suggests that when a topic is at odds with one's cultural identity a greater understanding of that topic does not increase acceptance of that topic (Kahan 2015). Research focusing on the resistance to contemporary controversial topics has shown that fact-based arguments are often ineffectual for increasing acceptance of facts about controversial topics, such as climate change and evolution. People who understand the arguments for evolution and climate change nonetheless tend to resist

\footnotetext{
*Correspondence: evansem@umich.edu

${ }^{2}$ University of Michigan, Center for Human Growth and Development, Ann Arbor, MI, USA

Full list of author information is available at the end of the article
}

the validity of arguments that conflict with their cultural identity (Kahan 2015; Lewandowsky and Oberauer 2016). However, providing familiar examples with practical implications may help improve understanding regardless of acceptance. In the context of evolution, evolutionary medicine (the application of modern evolutionary theory to understanding health and disease) provides such examples and should increase understanding of a core component of evolution, natural selection. Therefore, a course on evolutionary medicine provides a context for exploring the complex relationship between understanding natural selection, accepting evolution, and increased understanding of natural selection after instruction. We summarize research on evolutionary medicine as a 
potential teaching tool for increasing understanding of natural selection, then describe the differences between terms used in evolution education that are often confused and conflated (belief, acceptance, understanding, and knowledge). Next, we review studies of how cultural/ attitudinal and cognitive factors influence understanding and acceptance of evolution. Finally, we describe a study that explores the influence of cultural/attitudinal factors and cognitive factors on students' acceptance of evolution at the start of an evolutionary medicine course and how these factors influence students' ability to learn natural selection over the course.

\section{Evolutionary medicine as a teaching tool}

Research suggests that the provision of a motivational framework that encourages students to personally identify with and invest in the topic may be an effective teaching tool. Evolutionary medicine has that potential. By making students aware of the utility of evolutionary theory in everyday life (Futuyma 1995; O’Brien et al. 2009), particularly in health-related decision making, evolutionary medicine can directly engage students, including those who may not usually accept evolutionary ideas. Recent articles have examined the various ways that this could be accomplished in high school (Beardsley et al. 2011) and college (Meikle and Scott 2011). Evolutionary medicine has also been proposed as an essential component of the medical school curriculum (Alcock and Schwartz 2011; Jenkins and Antolin 2011; Labov 2011; Nesse et al. 2010; Stearns et al. 2010).

\section{Belief, understanding, acceptance, and knowledge}

The status of evolution as one of the most poorly accepted and understood scientific theories is well-documented. In $2014,42 \%$ of the US public chose the statement "God created human beings in their current form within the last 10,000 years" as the option that most closely aligned with their viewpoint (Newport 2014). Numerous studies also demonstrate widespread misunderstanding of natural selection among high school biology teachers (e.g., Nehm et al. 2009) as well as high school students (e.g., Lawson and Worsnop 1992). Moreover, basic misconceptions of evolution are consistently endorsed or expressed by a broad range of the public, including adult visitors to natural history museums (Evans et al. 2010), science graduate students (Gregory and Ellis 2009), and medical students (Bishop and Anderson 1990).

Misunderstandings of natural selection and other evolutionary mechanisms are not necessarily related to the pervasive resistance to the idea of evolutionary origins, especially of humans (Evans et al. 2010; Hermann 2012; Kahan 2015). Inconsistent use of terms-such as acceptance, belief, understanding, and knowledge-and difficulties measuring those constructs, has made it challenging to achieve consensus on the nature of the relationship between understanding and acceptance (Smith 2009; Southerland et al. 2001). Some researchers distinguish belief in evolution from acceptance, with belief based solely on intuition or faith, while acceptance is said to require an evaluation of the evidence (Abraham et al. 2012; Akyol et al. 2012; Ingram and Nelson 2006; Nadelson and Southerland 2009; Sinatra et al. 2003). However, other researchers, use the terms synonymously and argue that the distinction is not useful (Nehm et al. 2009). Even college-level evolution instructors use inconsistent definitions of acceptance of evolution and understanding of evolution (Barnes and Brownell 2016). The meaning of 'knowledge of evolution' has also been debated (Cobern 2004; Smith and Siegel 2004; Southerland et al. 2001). Some authors describe knowledge in philosophical terms as 'justified true belief' that requires understanding and belief and/or acceptance (Abraham et al. 2012; Cobern 2004; Sinatra et al. 2003; Southerland et al. 2001). Others equate knowledge solely with understanding, whether or not it is accompanied by adequate justifications or belief and/or acceptance (Carter and Wiles 2014; Deniz et al. 2008).

Relatedly, although a range of instruments have been used to measure acceptance and understanding of evolution, their operationalization is suboptimal. For instance, the measure of acceptance of evolutionary theory (MATE) (Rutledge and Warden 1999) is widely used to measure acceptance (Akyol et al. 2012; Barone et al. 2014; Carter and Wiles 2014; Ha et al. 2012), however, many items on this scale conflate acceptance with understanding (Glaze and Goldston 2015; Smith 2009).

To avoid this problem, a straightforward measure of acceptance that does not also measure understanding of evolutionary facts was used in this study (see Spiegel et al. 2012). Acceptance was operationalized as the extent to which a student agrees that evolutionary processes explain the origin of diverse species, including humans, as this contentious issue is the one most likely to challenge religious belief and individual identity. Understanding of natural selection was operationalized as the extent to which a student answers factual and conceptual questions about natural selection correctly. We used the conceptual inventory of natural selection (CINS) to measure student understanding of natural selection (Anderson et al. 2002). It is comprehensive, widely used, and, importantly, it measures understanding of natural selection in the context of a diversity of organisms. Prior educational exposure to evolution was operationalized as the extent to which a student has been exposed to evolutionary ideas in the past. 


\section{Intuitive cognitive biases}

Cognitive biases are conceptualized as early emerging intuitive conceptual frameworks that may benefit the young learner by focusing attention on the relevant input (Wellman and Gelman 1998). Such biases persist for adult learners as well potentially impeding understanding of evolution (Evans 2001) and other counterintuitive scientific concepts (Bloom and Weisberg 2007).

For instance, teleological reasoning is the tendency to view natural phenomena as purposeful or directed towards a goal (e.g., Kelemen 2012). In the case of natural selection, this could be a "goal" of health and longevity or other perceived "needs" of the organism. It is one of the three cognitive biases most often implicated in resistance to evolutionary thinking (the others being essentialism and intentionality) and has been consistently linked to students' difficulties understanding natural selection (e.g., Evans 2001, 2013; Nehm and Reilly 2007). A classic example of this pattern is the "Lamarckian" explanation for the existence of the giraffe's long neck (e.g., Evans 2013), which is that giraffes needed long necks to reach leaves at the top of the trees. In contrast, there is no implicit goal or purpose built into the explanation provided by natural selection, which is that there is natural variation in the population and those animals with longer necks had greater reproductive success in a particular environment. Thus, we also included a measure of students' teleological reasoning in the study. Teleological biases differ from those reasoning biases that refer explicitly to the intentions of the organism (e.g., 'the finches wanted bigger beaks, so they exercised them') or to a purposeful and intelligent external agent (e.g., 'God made it that way') (Evans et al. 2012).

\section{Cultural, attitudinal, and educational factors}

Cultural and attitudinal factors can reinforce and extend cognitive biases. Religiosity, family education level, ingroup attitudes, and prior exposure to negative media on evolution all contribute to low acceptance, which, in turn, can increase resistance to learning about evolution (Evans 2013; Barnes et al. 2017b; Brem et al. 2003), so we also include measures of religiosity and family demographic and attitudinal factors.

While there seems to be a positive relationship between the number of college biology courses taken and an understanding of evolution (Nadelson and Southerland 2009; Rice et al. 2011), the influence of one or two semesters of evolution instruction is less clear. Short and Hawley (2015) found that student misconceptions of evolution decreased over a semester in an evolutionary psychology class; however, the same study also found that student misconceptions about evolution increased over a semester in an introductory biology class. Similarly,
Abraham et al. (2012) found that while some student misconceptions of evolution decreased over a semester of college biology instruction, others increased. These uncertainties led us to include a subjective measure of prior educational exposure to evolution to augment the measure of the number of biology courses taken.

\section{Research questions}

Many studies have examined factors influencing undergraduates' understanding of evolution including studies that have examined cultural/attitudinal factors and cognitive factors, but none have studied the relative influence of these factors on students' learning of evolution over an undergraduate course in evolutionary medicine. Our main research question was whether intuitive cognitive biases and students' initial acceptance of evolution influenced their learning of natural selection in a course on evolutionary medicine. We assessed the relationships among the cultural/attitudinal factors and cognitive factors before the course. After the course, we again measured students' understanding of natural selection and teleological reasoning, while controlling for their initial understanding of natural selection, in order to determine which variables influenced learning gains of natural selection over the semester.

Unlike other studies (e.g., Beardsley et al. 2011), we used the full CINS assessment of natural selection understanding (Anderson et al. 2002). This measure allowed us to assess whether students generalized their understanding of natural selection to adaptations using examples not presented in the course materials. As part of the pre-test, in addition to demographic questions, we assessed students' acceptance of evolution, religiosity, prior exposure to evolutionary concepts, and their parents' beliefs and educational levels. The CINS was given as a pre- and post-test along with a measure of students' intuitive teleological reasoning.

\section{Methods \\ Participants}

Participants were students from two consecutive years of a semester-long course on evolutionary medicine at a selective public research university $(N=190$, mean age $=19.5$ years; $72 \%$ female; $63 \%$ non-Hispanic white). Sixty-one percent of the students were first years or sophomores, $37 \%$ were juniors or seniors, while $2 \%$ did not report a class year; $63 \%$ had taken at least one previous college level biology class. Students' stated career goals included: $62 \%$ medicine/public health, $9.5 \%$ psychology/ social work, $9.5 \%$ other, $4 \%$ biology, $11 \%$ undecided. Religious identification included: 30\% Catholic, 13\% fundamentalist Christian, $11 \%$ other Protestant, 10\% other, 9\% Jewish, 3\% Eastern religion, 3\% Muslim, and 19\% none. 
One hundred and ninety students (97\% response rate) completed the pre-test, 144 ( $79 \%$ response rate) the posttest, while 129 (66\% response rate) provided complete pre-post data over the two assessments. There were no significant differences on any of the pre-test measures between those students who did or did not complete the post-test. In each analysis, the number of students included may differ depending on how many students had a completed data set for that particular analysis.

\section{Course description}

This course was co-taught by the same two instructors for two semesters. Both were experienced instructors who had taught the same course in previous years. The course goals were to teach core principles of evolutionary biology and their application to problems in medicine and public health. The goal of the class was to develop critical thinking about why mechanisms in the body appear to be vulnerable to disease, from an evolutionary perspective. Thus, there was a strong emphasis on teaching the principles of adaptation and maladaptation, and methods for testing hypotheses about the origins and tradeoffs of biological adaptations (See Additional file 1: Table S1 for list of topics and readings).

The course format relied on lectures for a portion of most classes, augmented by classroom discussion and exercises that engaged individuals actively. Students also had textbook readings, weekly discussions in small sessions with graduate assistants, several laboratory exercises, and a field trip. Unscheduled in-class quizzes, five over the course of the semester, encouraged students to do the readings, while a midterm and a final exam tested content knowledge. Students also wrote a term paper where they chose a human disease to explain in terms of the evolutionary underpinnings of vulnerability to that disease.

\section{Procedure}

In a 15 to 20 -min session on the first day of class, students provided informed consent, demographic information, and completed a pre-test. The post-test, with a subset of the same measures on the pre-test (see Table 1), was completed in a 10 to 15 -min session on the last day of class. One researcher (EME), who was not one of the course instructors, collected all data and students understood that the researcher would have no access to or influence over course grades. The course instructors did not know which students agreed to participate in the study, minimizing pressure to participate and possible influences of social desirability effects.

\section{Measures}

The measures are summarized in Table 1, along with reliability coefficients, for applicable scales. Scales with fewer than 10 items often have low alpha values, thus in cases where the scales have fewer than 10 items, we report their mean inter-item correlations in conjunction with Cronbach's Alpha (MIIC: optimal range .2-.4). For the CINS, which is a 20-item scale, we report only Cronbach's alpha (Table 1). For single item measures (student religiosity and prior educational exposure) and two item measures in which inter-item correlation does not signify

Table 1 Study measures: inter-item correlation ranges (IICR), Cronbach's alpha, and whether the measure was used during pre-test and/or post-test ( $N / A$ not applicable)

\begin{tabular}{|c|c|c|c|c|}
\hline Measures & Pre-test & Post-test & IICR & Alpha \\
\hline Final semester grade: students'final percent grade in the evolutionary medicine course & N/A & N/A & N/A & N/A \\
\hline $\begin{array}{l}\text { Parental educational level (two items): mean of mothers' and fathers' highest educational levels (scale 1-5: some } \\
\text { high school to graduate school) }\end{array}$ & $\checkmark$ & & N/A & $\mathrm{N} / \mathrm{A}$ \\
\hline \multicolumn{5}{|l|}{ Cultural/attitudinal measures } \\
\hline $\begin{array}{l}\text { Parental attitude towards evolution (two items): mean agreement (scale 1-5: disagree to agree): what attitude } \\
\text { do you think your (1) father or guardian has toward evolution? (2) mother or guardian has toward evolution? }\end{array}$ & $\checkmark$ & & N/A & N/A \\
\hline Student religiosity (one item): how important is religion in your life? (scale 1-4: not important to very important) & $\checkmark$ & & $\mathrm{N} / \mathrm{A}$ & N/A \\
\hline $\begin{array}{l}\text { Student acceptance of evolution (three items): mean agreement (scale 1-5: disagree to agree): do you think that } \\
\text { evolutionary principles explain the origins of (1) reptiles (2) humans (3) viruses? }\end{array}$ & $\checkmark$ & & $.60-.78$ & .86 \\
\hline \multicolumn{5}{|l|}{ Cognitive measures } \\
\hline $\begin{array}{l}\text { Prior educational exposure (one item): how much have you learned about evolution? (scale 1-5: not much to a } \\
\text { lot) }\end{array}$ & $\checkmark$ & & $\mathrm{N} / \mathrm{A}$ & $\mathrm{N} / \mathrm{A}$ \\
\hline $\begin{array}{l}\text { Teleological reasoning (three items): mean agreement (scale 1-5: disagree to agree): (1) natural selection shapes } \\
\text { health and longevity; (2) evolutionary changes arise in response to the needs of organisms to adapt to its } \\
\text { environment; (3) natural selection shapes healthy inclinations }\end{array}$ & $\checkmark$ & $\checkmark$ & $.26-.45$ & .60 \\
\hline $\begin{array}{l}\text { Natural selection understanding (20 items): CINS, multiple choice test in which participants select the best } \\
\text { answer out of four responses (score }=\text { total number correct) }\end{array}$ & $\checkmark$ & $\checkmark$ & $\mathrm{N} / \mathrm{A}$ & .71 \\
\hline
\end{tabular}


reliability (parental education level and parental attitude towards evolution) we do not report reliability data. Table 1 also describes which measures were used in the pre-test and which measures were used in the post-test.

\section{Validity and reliability}

For student acceptance of evolution, we asked students in the pretest whether they agreed that evolutionary principles explained the origin of viruses, reptiles, and humans (inter-item correlation range $=.60-.78$ ). This was based on a measure validated in Spiegel et al. (2012), which explored whether visitors to a museum changed their conceptions of evolution following their exposure to an exhibit on evolution. Most of the variables in the Spiegel et al. (2012) study were based on open-ended scenarios, but the visitors were also asked the same three Likert scale questions on their acceptance of evolutionary origins as in the current study, though the organisms differed, being insects, birds, and humans. These were combined into a single highly reliable scale, acceptance of evolutionary origins (Cronbach's alpha $=.91$ ), which demonstrated good construct validity as it was significantly negatively correlated with participant religiosity $(\mathrm{r}=-.33 ; p<.001)$ and positively correlated with participants' views on the importance of understanding evolution $(\mathrm{r}=.50 ; p<.001)$. In the current study, this measure was asked before the course began and the reliability of the measure was high (Cronbach's alpha $=.86$ ), as was the construct validity, indicated by the significant positive and negative relationships with the other key measures (see Table 3).

How much students reported learning about evolution before the course (prior educational exposure), was significantly related to the number of evolution courses the student completed in high-school $(M=2, S D=1.06$; $r(189)=.26, p<.001)$, and in college, $(M=1.24$, $S D=1.63 ; r(186)=.38, p<.001$.). Unlike prior educational exposure, however, the number of completed high school courses in biology and college courses with evolution did not correlate significantly with key variables, which challenged its validity as a measure of prior learning with this population of students, thus they were excluded from further analyses and prior educational exposure was used instead.

Teleological reasoning was operationalized as student agreement with three progressive/need based statements about evolution, selected from a corpus of misconceptions voiced by students in the instructor's previous classes on this topic. The conceptual and empirical framework informing this measure (see Johnson and Morgan 2016) included the following: (1) items were student misconceptions about evolutionary medicine, identified by the instructor in previous iterations of the course
(2) the misconceptions could be conceptualized as teleological; in particular, we focused on items that implied a goal directed process, a key feature of teleological reasoning identified by Mayr (1982, p. 48) and (3) the items had reasonable reliability (given that they assessed different kinds of misconceptions). Of 14 misconceptions included in the pre-test, three met these criteria.

Of the three statements included in this measure, the first (natural selection shapes health and longevity) and third (natural selection shapes healthy inclinations) focused on a common misconception (based on "survival of the fittest") that natural selection shapes healthy outcomes and/or increases longevity. This is only true to the extent that selection shapes inclinations that increase reproductive success in ancestral environments. However, any allele that increases reproductive success will spread even if it decreases health outcomes and longevity. The second statement (evolutionary changes arise in response to the needs of organisms to adapt to its environment) refers to a common misunderstanding that organisms direct evolution to meet their needs (e.g., the classic Lamarckian explanation of the "giraffe's long neck" - see the "Introduction and background"). All these statements are teleological in the sense that they imply that natural selection (AKA evolution) is goal-directed and purposeful, in that it shapes future outcomes and (as such) is responsive to the survival needs of the organism, demonstrating good face validity.

The inter-item correlation of the teleological measure is adequate (.26-.45), given that each statement represented a different domain (health, longevity, the organism's needs). It also demonstrates good construct (theoretical) validity; the teleological measure is significantly negatively related to natural selection understanding and the final course grade but unrelated to the other measures, which was predicted.

Natural selection understanding was measured using the conceptual inventory for natural selection, or CINS, and has been previously validated with college students (Anderson et al. 2002) (Cronbach's alpha $=.71$ ). The mean score on this measure for a community college student sample was $8.21(S D=3.07)$ (Anderson et al. 2002).

\section{Analyses}

We first used Pearson correlations (two-tailed) to establish baseline relationships between each variable at pretest. However, to determine the relative influence of each variable on students' incoming acceptance of evolution at pre-test, their incoming understanding of natural selection at pre-test, and changes in understanding of natural selection over the semester, we ran three independent multiple regressions using relevant variables as predictors of the dependent variable in each regression. 
Multiple regression is appropriate for this analysis to estimate the unique variance explained by each variable, when all other variables are held constant (Aiken et al. 1991).

\section{Results}

Pre-test: attitudes and understanding

At the beginning of the course, student acceptance of evolution was high; on a scale of 1-5 students scored an average of 4.11. Student religiosity was close to neutral with students scoring an average of 2.43 on a 1-4 scale. Students showed a high endorsement of teleological reasoning ( 3.78 average on a $1-5$ scale) and low understanding of natural selection (13.90 average on a 0-20 scale). Ranges, means, and standard deviations of all variables at pre-test are reported in Table 2. We first examined the relationships between parent demographics, student and parent attitudinal measures, students' prior educational exposure, student natural selection understanding, and student teleological reasoning measures before students were exposed to the course material. Students entering

Table 2 Descriptive statistics of pre-test variables

\begin{tabular}{lrrrrr}
\hline & M & Min & Max & SD & N \\
\hline Parent education level & 4.13 & 1 & 5 & .85 & 189 \\
Parent attitude towards evolution & 3.80 & 1 & 5 & 1.05 & 189 \\
Student religiosity & 2.43 & 1 & 4 & 1.02 & 190 \\
Student acceptance of evolution & 4.11 & 1 & 5 & .82 & 188 \\
Student prior educational exposure & 3.07 & 1 & 5 & .93 & 189 \\
Student teleological reasoning & 3.78 & 1 & 5 & .81 & 186 \\
Student natural selection understanding & 13.90 & 6 & 20 & 3.50 & 182 \\
\hline
\end{tabular}

this course in evolutionary medicine had better scores on the CINS measure of natural selection understanding than those of the community college students sampled in Anderson et al. (2002) research.

\section{Correlations}

As seen in Table 3, at pre-test, students who had higher acceptance of evolution scores had parents with higher educational levels who were also more likely to accept evolution. Student religiosity and parent educational level were not significantly correlated. Students reporting higher levels of prior educational exposure to evolution obtained somewhat higher scores on the measures of natural selection understanding and acceptance of evolution, and lower scores on religiosity. Students who obtained higher scores on the measure of natural selection understanding at pre-test were less religious and more likely to accept evolution. Their parents were also more likely to accept evolution. Students with a better understanding of natural selection also had higher levels of prior educational exposure to evolution and were less likely to endorse teleological reasoning. However, these correlations do not consider the influence of other correlated variables so we conducted multiple regression analyses to determine the relative influence of each variable, controlling for all other variables, on student acceptance of evolution and student understanding of natural selection at pre-test.

\section{Student acceptance of evolution}

To control for all other variables and illustrate the relative influence of each variable on students' incoming acceptance of evolution, we conducted a multiple linear

Table 3 Pearson correlations (two-tailed) among pre-test variables, assessed before exposure to course material

\begin{tabular}{|c|c|c|c|c|c|c|}
\hline Measures & $\begin{array}{l}\text { 1. Parent educa- } \\
\text { tion level }\end{array}$ & $\begin{array}{l}\text { 2. Parent attitude } \\
\text { evolution }\end{array}$ & $\begin{array}{l}\text { 3. Student } \\
\text { religiosity }\end{array}$ & $\begin{array}{l}\text { 4. Student acceptance } \\
\text { evolution }\end{array}$ & 5. Prior exposure & $\begin{array}{l}\text { 6. Teleological } \\
\text { reasoning }\end{array}$ \\
\hline \multicolumn{7}{|c|}{ Demographic and cultural/attitudinal measures } \\
\hline $\begin{array}{l}\text { 1. Parental educa- } \\
\text { tional level }\end{array}$ & - & & & & & \\
\hline $\begin{array}{l}\text { 2. Parental attitude } \\
\text { evolution }\end{array}$ & $.314^{* * *}$ & - & & & & \\
\hline $\begin{array}{l}\text { 3. Student religios- } \\
\text { ity }\end{array}$ & -.062 & $-.332^{* * *}$ & - & & & \\
\hline $\begin{array}{l}\text { 4. Student accept- } \\
\text { ance evolution }\end{array}$ & $244^{* *}$ & $.679^{* * *}$ & $-.457^{* * *}$ & - & & \\
\hline \multicolumn{7}{|l|}{ Cognitive measures } \\
\hline 5. Prior exposure & .091 & $200^{* *}$ & $-.211^{* *}$ & $.248^{* * *}$ & - & \\
\hline $\begin{array}{l}\text { 6. Teleological } \\
\text { reasoning }\end{array}$ & .016 & .043 & -.089 & .100 & -.038 & - \\
\hline $\begin{array}{l}\text { 7. Natural selection } \\
\text { understanding }\end{array}$ & .051 & $.213^{* *}$ & $-.218^{* *}$ & $.156^{*}$ & $.304^{* * *}$ & $-.295^{* * *}$ \\
\hline
\end{tabular}

${ }^{*} \mathrm{p}<.05,{ }^{* *} \mathrm{p}<.01,{ }^{* * *} \mathrm{p}<.001$ 
regression (see Table 4 for a summary of coefficients, standard errors, and statistical significance): $R^{2}=.50$ $(R=.71) ; F(6,169)=28.50, p<.001$ (Adjusted $\left.R^{2}=.49\right)$. Together, these variables accounted for $49 \%$ of the variance in student acceptance of evolution scores, with significant unique variance contributed by two of the attitudinal variables, parent attitude toward evolution (positively) and student religiosity (negatively). Interestingly, parent attitude towards evolution predicted student acceptance of evolution more than religiosity indicating that parent attitudes may be more important for student acceptance of evolution than strength of personal religious beliefs among this population. Almost none of the cognitive variables contributed unique variance to students' acceptance of evolution, except prior educational exposure, but this variable was a far weaker predictor of acceptance of evolution than either of the cultural/attitudinal variables (Table 4).

Given that individuals are more likely to reject the evolutionary origins of humans versus other organisms we were interested to see if these results would be different if we separated student acceptance of human evolution from that of reptiles and viruses. Therefore, we ran these analyses again with the dependent variable as the single item from our scale that inquired about human evolution and then again with the dependent variable being student scores on acceptance of evolution of viruses and lizards. The results of these analyses were not different from the results reported in Table 4. The same was determined for all subsequent regression analyses. The frequency distributions of each measure are reported in Fig. 1, which illustrate the similarities in scores between the three different items and the aggregate acceptance of evolution scores.

Table 4 Results from a multiple linear regression of student incoming acceptance of evolution on all pre-test variables

\begin{tabular}{lccl}
\hline & B & SE B & $\boldsymbol{\beta}$ \\
\hline Intercept & 2.59 & .42 & $\mathrm{~N} / \mathrm{A}$ \\
Demographic and cultural/attitudinal measures & & \\
1. Parental educational level & .04 & .05 & .04 \\
2. Parental attitude towards evolution & .40 & .05 & $.52^{* * *}$ \\
3. Student religiosity & -.21 & .05 & $-.27^{* * *}$ \\
Cognitive variables & & & \\
4. Prior educational exposure & .11 & .05 & $.12^{*}$ \\
5. Teleological reasoning & .04 & .06 & .04 \\
6. Natural selection understanding & -.01 & .01 & -.04 \\
Adjusted $\mathrm{R}^{2}$ & .49 & & \\
\hline . & &
\end{tabular}

${ }^{*} p<.05,{ }^{* *} p<.01,{ }^{* * *} p<.001$

\section{Natural selection understanding}

To control for all other variables and illustrate the relative influence of each variable on student incoming understanding of natural selection, we conducted a multiple linear regression (see Table 5 for a summary of coefficients, standard errors, and statistical significance): $R^{2}=.24(R=.49) ; F(6,169)=8.788, p<.001$ (Adjusted $\left.R^{2}=.21\right)$. Together, these variables accounted for $21 \%$ of the variance with significant unique variance contributed by one of the cultural/attitudinal variables only; student religiosity (negatively). Both cognitive variables, prior educational exposure (positively) and teleological reasoning (negatively), contributed unique variance. Student religiosity was a weaker predictor of understanding of natural selection than were the cognitive variables. In summary, while cultural/attitudinal measures mainly predicted students' acceptance of evolution, cognitive measures were the main predictors of natural selection understanding.

\section{Pre- to post-test: natural selection understanding and teleological reasoning}

Paired sample $t$ tests were conducted on pre- and posttest natural selection understanding and teleological reasoning scores to determine whether they had changed after exposure to course material. Both analyses indicated a statistically significant change over the semester: an increase in natural selection understanding $($ Mpre $=14.09, S D=3.53 ;$ Mpost $=16.41, S D=3.13)$, $t(143)=-.10 .35, p<.001$, and a decrease in teleological reasoning (Mpre $=3.80, S D=.81 ;$ Mpost $=2.44$, $S D=.86), t(147)=.14 .80, p<.001$.

\section{Learning gains in natural selection understanding over the course}

Natural selection understanding at post-test was significantly correlated with the following pre-test measures: parental attitude towards evolution $(r=.26 ; p=.001)$, student religiosity $(r=-.23 ; p=.002)$, student acceptance of evolution $(r=.21 ; p=.005)$, prior educational exposure $(r=.23 ; p=.003)$, and pre-test natural selection understanding $(r=.68 ; p<.001)$, as well as the post-test measure of teleological reasoning $(r=-.39$; $p<.001)$. We conducted a multiple linear regression to determine the relative influence of each variable, independently of the others, on the post-test natural selection understanding score. Because we control for pre-test natural selection understanding in this regression, we are in effect, determining the relative influence of all other variables on student learning gains in natural selection understanding over the course. Overall, $50 \%$ of the variance was explained: $R^{2}=.53(R=.73) ; F(7$, $132)=21.0, p<.001$ (Adjusted $R^{2}=.50$ ). Only natural 

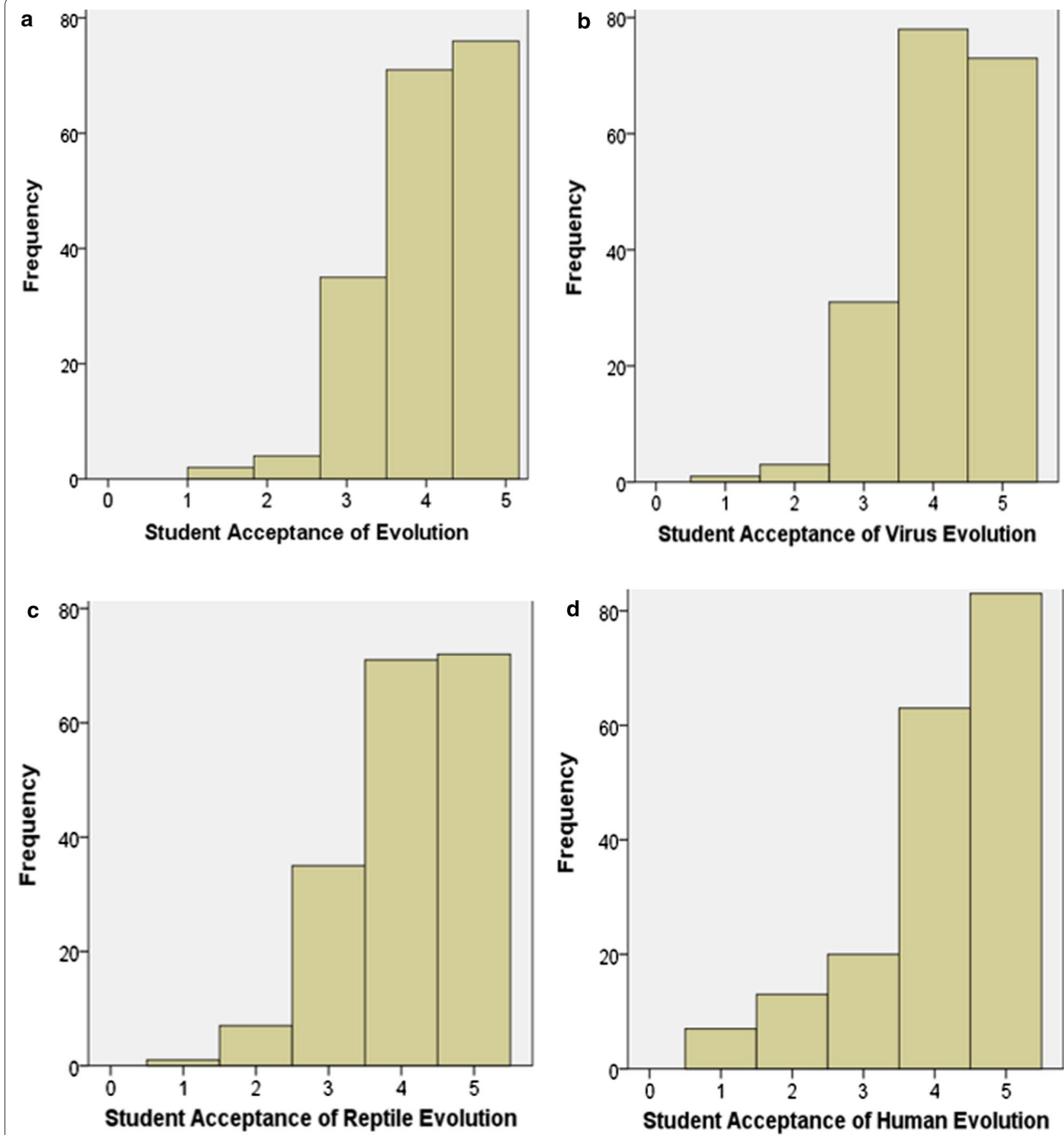

Fig. 1 Frequency distributions of student acceptance of evolution scores 1 lowest acceptance and 5 highest acceptance a frequency distribution of student scores on the combined measure of acceptance of evolution (virus + reptiles + humans/3) b frequency distribution of student scores on the single question on acceptance of virus evolution c frequency distribution of student scores on the single question on acceptance of reptile evolution and $\mathbf{d}$ frequency distribution of student scores on the single question of acceptance of human evolution

selection understanding-pre $(\beta=.58 ; p<.001)$ and teleological reasoning-post $(\beta=-.24 ; p<.001)$ contributed significant unique variance. Results are summarized in Table 6.
Learning gains in understanding of natural selection were predicted by the cognitive variables, but not by the cultural/attitudinal variables. Although students were less likely to endorse teleological reasoning at the end 
Table 5 Results from a multiple linear regression of student incoming understanding of natural selection on all pre-test variables

\begin{tabular}{llll}
\hline & B & SE B & $\boldsymbol{\beta}$ \\
\hline Intercept & 16.21 & 2.27 & N/A \\
Demographic and cultural/attitudinal measures & & \\
1. Parental educational level & .14 & .29 & .03 \\
2. Parental attitude towards evolution & .45 & .31 & .13 \\
3. Student religiosity & -.63 & .27 & $-.18^{*}$ \\
4. Student acceptance of evolution & -.30 & .43 & -.07 \\
Cognitive variables & & & \\
5. Prior educational exposure & 1.01 & .27 & $.27^{* * *}$ \\
6. Teleological reasoning & -1.31 & .29 & $-.30^{* * *}$ \\
Adjusted $R^{2}$ & .21 & & \\
\hline
\end{tabular}

${ }^{*} \mathrm{p}<.05,{ }^{* *} \mathrm{p}<.01,{ }^{* * *} \mathrm{p}<.001$

Table 6 Results from a multiple linear regression of student post-test understanding of natural selection

\begin{tabular}{llll}
\hline & B & SE B & $\boldsymbol{\beta}$ \\
\hline Intercept & 12.45 & 1.80 & $\mathrm{~N} / \mathrm{A}$ \\
Demographic and cultural/attitudinal measures & & \\
1. Parental educational level & -.26 & .23 & -.07 \\
2. Parental attitude towards evolution & .43 & .23 & .15 \\
3. Student religiosity & -.26 & .21 & -.09 \\
4. Student acceptance of evolution & -.233 & .247 & -.079 \\
Cognitive variables & & & \\
5. Prior educational exposure & -.01 & .22 & -.00 \\
6. Teleological reasoning-post & -.81 & .21 & $-.24^{* * *}$ \\
7. Natural selection understanding-pre & .50 & .06 & $.58^{* * *}$ \\
Adjusted $R^{2}$ & .50 & & \\
* & & &
\end{tabular}

${ }^{*} \mathrm{p}<.05,{ }^{* *} \mathrm{p}<.01,{ }^{* * *} \mathrm{p}<.001$

of the course, continued endorsement of intuitive teleological explanations for evolutionary change negatively predicted students' learning gains in understanding of natural selection.

\section{Final semester grade}

We further conducted similar analyses on the final semester grades to assess the influence of natural selection understanding-post on course grades. We did this to provide evidence to assess whether students' mastery of course material was indeed dependent on their mastery of understanding natural selection. Final semester grades $(N=172)$ ranged from 70.5 to $98.2(M=87.64$, $S D=5)$. Both significantly correlated variables, teleological reasoning-post $(r=-.24 ; p=.004)$ and natural selection understanding-post $(r=.42 ; p<.001)$ were simultaneously regressed on the final course/grade score; they explained $17 \%$ of the final semester grade: $R^{2}=.18$ $(R=.43) ; F(2,146)=15.87, p<.001$ (Adjusted $\left.R^{2}=.17\right)$. Natural selection understanding-post, only, contributed significant unique variance $(\beta=.38 ; p<.001)$ demonstrating a significant role for a principled understanding of natural selection in students' mastery of the course material.

\section{Discussion}

Undergraduate students in this study completed a course on evolutionary medicine that offered a human-centered narrative, which increased learning of natural selection and decreased teleological reasoning over the semester. Importantly, this course succeeded in conveying key evolutionary content, natural selection, regardless of students' incoming acceptance of evolution. Their understanding of natural selection improved over the semester, as measured with an instrument that included questions on content unrelated to course material but nonetheless explained significant variance in grades. Overall, these findings demonstrate that students generalized an understanding of natural selection gained in a course on evolutionary medicine to content more typically found in standard evolutionary biology courses. Relatedly, over the same time-frame, they significantly decreased their reliance on intuitive teleological reasoning.

\section{Key findings}

First, students with a broad range of scores on a measure of acceptance of evolution are capable of learning about evolutionary medicine in general, and natural selection in particular. Second, students' cognitive biases significantly interfered with learning. We compiled a measure of students' acceptance of evolution in which they merely had to indicate whether they agreed that evolutionary principles explained the origin of diverse species (including humans). This measure did not assess students' knowledge of evolution facts; in this respect, it differs from extant measures of students' acceptance of evolution (e.g., Rutledge and Warden 1999), which tend to conflate acceptance and understanding. Conversely, our measure of natural selection understanding focused entirely on student understanding of evolutionary facts and concepts, but did not address student attitudes toward evolution.

We were intrigued to discover that when using multiple regression analyses to control for various factors, parental attitude towards evolution (but not parent educational level) positively predicted students' acceptance of evolution but had no independent effect on students' understanding of natural selection. This is in line with recent studies, which establish that education level, per se, plays a minor role in the acceptance of evolution, while the 
attitudes of family and friends play a more significant role (Hill 2014). Parents with low education levels may be more likely to have low acceptance of evolution, but it is their attitude that is driving students' acceptance levels, not their level of education. Conversely, prior educational exposure to evolution (positively) and intuitive teleological reasoning (negatively) predicted understanding of natural selection, but neither had a large effect on acceptance of evolution. While student religiosity affected both measures negatively, the amount of variance explained by religiosity was much higher for acceptance of evolution than for understanding of natural selection. Additionally, the two key measures, evolution acceptance and understanding of natural selection were not significantly related to each other once the variance explained by other variables was excluded. Finally, student learning gains in natural selection at the end of the semester were uniquely predicted by the cognitive variables alone: teleological reasoning and pre-test natural selection understanding. This disassociation between the cognitive and attitudinal factors makes it possible for courses that focus on evolutionary mechanisms, such as natural selection, to be successful, regardless of students' prior beliefs and family attitudes about evolution.

Persistent tendencies toward teleological reasoning were associated with a decrease in college students' ability to learn natural selection. At the end of the course, students were significantly less likely to endorse teleological reasoning, although those who continued to endorse such explanations for evolutionary change did worse on the post-test measure of natural selection understanding. These findings imply that instruction aimed at alerting students to the possible negative effects of their intuitive endorsement of teleological explanations should be given more consideration and that it may increase learning gains.

\section{Limitations and future directions}

We did not have a comparison group of students who were learning evolution outside of the context of evolutionary medicine, making causal inferences about the efficacy of teaching evolutionary medicine specifically, as opposed to other evolution instructional methods difficult. However, we limit our conclusions about the efficacy of evolutionary medicine in this manuscript for that reason.

An additional limitation was that our measure of understanding was limited to natural selection. It would have been useful to examine whether students' understanding of macroevolutionary processes changed over the semester and how attitudinal/cultural and cognitive variables were related to this change (Nadelson and Southerland
2009). However, given that this course was not focused on macroevolutionary principles, we are doubtful that we would have seen similar gains on a measure of understanding of macroevolution and therefore this course would not have been the proper context to test these kinds of hypotheses. Further, due to the absence of a teleological reasoning measure explicitly focused on evolutionary medicine, we used responses to three questions on this topic (out of a corpus of 12 questions) to assess students' tendency to believe that evolution is directed towards a goal. Although this is a more narrowly defined construct than teleological reasoning in general, it is one of the key constructs identified by Mayr (1982). Validated measures of different aspects of teleological reasoning are needed and should be used for future studies.

Additionally, overall in this course students' incoming acceptance of evolution was high; some students came in with only moderate levels of acceptance, but few of them had very low levels of acceptance (Fig. 1). Future research should explore if these results are robust with a population of students with lower initial acceptance of evolution.

Finally, we did not assess changes in acceptance of evolution over the semester. The amount of time available for data collection was limited because we administered the pre- and post-test on the first and last day of class, respectively. Especially for the post-test, this meant limiting the number of measures to measures of understanding and teleological reasoning. Future research should also explore how these factors may influence a change in acceptance of evolution over the semester.

\section{Implications for instruction}

The disconnect between students' acceptance of evolution and their understanding of natural selection is in accordance with a recent body of research demonstrating that facts are not necessarily persuasive, particularly when they conflict with beliefs that are central to an individual's identity (e.g., Barnes et al., 2017a; Evans 2013; Kahan 2015). Instructors of courses that introduce controversial material, whether in the sciences or the social sciences, should be cognizant of this disconnect and try to adjust their delivery of course material accordingly. Our main recommendation based on these data is that teaching students about intuitive cognitive biases, particularly teleological reasoning, could serve to make students more aware of this bias and perhaps reduce the tendency to use them when reasoning about natural selection. Such instruction could help students be more reflective about the language they use to describe evolutionary processes and could thus impact their understanding of natural selection. 


\section{Conclusion}

These data show that students with reasonably broad ranges of acceptance of evolution can understand natural selection if their tendency to use teleological reasoning is corrected. We also demonstrate with the pre-test data that a greater understanding of natural selection did not predict higher levels of acceptance of evolution, though religiosity and parental attitudes did. If instructors want to increase both understanding of natural selection and acceptance of evolution they may have to address both cognitive factors, such as teleological reasoning, as well as cultural factors such as family attitudes and religiosity.

\section{Additional file}

Additional file 1: Table S1. Topics covered in the evolutionary medicine course. WWGS = Why We Get Sick; PMG = Principles of Medical Genetics by Gelehrter, Collins, \& Ginsburg, 2nd edition; WSM = Why Sex Matters by Bobbi Low.

\section{Abbreviation}

CINS: conceptual inventory of natural selection.

\begin{abstract}
Authors' contributions
MEB performed statistical analyses and interpretation of data and drafted the manuscript. EME developed the research tools, collected data, ran statistical analyses, interpreted the data, wrote initial manuscripts and edited final drafts of the manuscript. AH was a graduate-student instructor on the course and helped in the initial stages of data analyses and manuscript drafting. SEB helped interpret data and was involved in revising the manuscript critically for important intellectual content. RN taught the course and helped to plan and carry out the study and to edit the final manuscript. All authors read and approved the final manuscript.
\end{abstract}

\begin{abstract}
Author details
${ }^{1}$ School of Life Sciences, Arizona State University, Tempe, AZ, USA. ${ }^{2}$ University of Michigan, Center for Human Growth and Development, Ann Arbor, MI, USA ${ }^{3}$ Department of Earth System Science, Stanford University, Stanford, CA, USA.
\end{abstract}

\section{Competing interests}

The authors declare that they have no competing interests.

\section{Consent for publication}

Consent was given for participant data to be published.

\section{Ethics approval and consent to participate}

All research was approved by the University's Institutional Review Board.

\section{Funding and acknowledgements}

We would like to thank the Center for Research on Learning and Teaching at the University of Michigan for providing funds for instrument development, data collection, and initial manuscript drafts (to EME and $\mathrm{AH}$ ) and the National Science Foundation (Grant Number DGE-1311230), which provided graduate student support for this manuscript (to MEB). Thanks to Alan Weder, MD, one of the teachers of the course who helped to plan and carry out the original study. The Center for Evolution and Medicine at Arizona State University helped to support the analysis and manuscript preparation.

\section{Publisher's Note}

Springer Nature remains neutral with regard to jurisdictional claims in published maps and institutional affiliations.
Received: 31 March 2017 Accepted: 15 September 2017

Published online: 02 October 2017

\section{References}

Abraham JK, Perez KE, Downey N, Herron JC, Meir E. Short lesson plan associated with increased acceptance of evolutionary theory and potential change in three alternate conceptions of macroevolution in undergraduate students. CBE-Life Sci Educ. 2012;11(2):152-64. doi:10.1187/ cbe.11-08-0079.

Aiken LS, West SG, Reno RR. Multiple regression: testing and interpreting interactions. New York: Sage; 1991

Akyol G, Tekkaya C, Sungur S, Traynor A. Modeling the interrelationships among pre-service science teachers' understanding and acceptance of evolution, their views on nature of science and self-efficacy beliefs regarding teaching evolution. J Sci Teacher Educ. 2012;23(8):937-57. doi:10.1007/s10972-012-9296-x.

Alcock J, Schwartz MD. A clinical perspective in evolutionary medicine: what we wish we had learned in medical school. Evol Educ Outreach. 2011;4(4):574-9. doi:10.1007/s12052-011-0362-1.

Anderson DL, Fisher KM, Norman GJ. Development and evaluation of the conceptual inventory of natural selection. J Res Sci Teach. 2002;39(10):95278. doi:10.1002/tea.10053.

Barone LM, Petto AJ, Campbell BC. Predictors of evolution acceptance in a museum population. Evol Educ Outreach. 2014;7(1):1-11. doi:10.1186/ s12052-014-0023-2.

Barnes ME, Brownell SE. Practices and perspectives of college instructors on addressing religious beliefs when teaching evolution. CBE-Life Sci Educ. 2016;15(2):ar18.

Barnes ME, Truong JM, Brownell SE. Experiences of Judeo-Christian students in undergraduate biology. CBE-Life Sci Educ. 2017a;16(1):ar15.

Barnes ME, Elser J, Brownell SE. Impact of a short evolution module on students' perceived conflict between religion and evolution. Am Biol Teacher. 2017b;79(2):104-11.

Beardsley PM, Stuhlsatz MAM, Kruse RA, Eckstrand IA, Gordon SD, Odenwald WF. Evolution and medicine: an inquiry-based high school curriculum supplement. Evol Educ Outreach. 2011;4(4):603-12. doi:10.1007/ s12052-011-0361-2.

Bishop BA, Anderson CW. Student conceptions of natural selection and its role in evolution. J Res Sci Teach. 1990;27(5):415-27. doi:10.1002/ tea.3660270503.

Bloom P, Weisberg DS. Childhood origins of adult resistance to science. Science. 2007;316:996-7.

Brem SK, Ranney M, Schindel J. Perceived consequences of evolution: College students perceive negative personal and social impact in evolutionary theory. Sci Educ. 2003;87(2):181-206. doi:10.1002/sce.10105.

Carter BE, Wiles JR. Scientific consensus and social controversy: exploring relationships between students' conceptions of the nature of science, biological evolution, and global climate change. Evol Educ Outreach. 2014;7(1):6. doi:10.1186/s12052-014-0006-3.

Cobern B. Apples and oranges: a rejoinder to Smith and Siegel. Sci Educ. 2004;13(6):583-9. doi:10.1023/B:SCED.0000042856.33782.7b.

Deniz H, Donnelly LA, Yilmaz I. Exploring the factors related to acceptance of evolutionary theory among Turkish preservice biology teachers: toward a more informative conceptual ecology for biological evolution. J Res Sci Teach. 2008;45(4):420-43. doi:10.1002/tea.20223.

Evans EM. Cognitive and contextual factors in the emergence of diverse belief systems: creation versus evolution. Cogn Psychol. 2001;42(3):217-66. doi:10.1006/cogp.2001.0749.

Evans EM. Conceptual change and evolutionary biology: taking a developmental perspective. In: Vosniadou S, editor. International handbook of research on conceptual change. New York: Routledge; 2013. p. 220-39.

Evans EM, Rosengren KS, Lane JD, Price KLS. Encountering counterintuitive ideas: constructing a developmental learning progression for evolution understanding. In: Rosengren KS, Brem SK, Evans EM, Sinatra GM, editors. Evolution challenges: integrating research and practice in teaching and learning about evolution. Oxford: Oxford University Press; 2012. p. 174-99. 
Evans EM, Spiegel A, Gram W, Frazier BF, Tare M, Thompson S, Diamond J. A conceptual guide to natural history museum visitors' understanding of evolution. J Res Sci Teach. 2010;47:326-53. doi:10.1002/tea.20337.

Futuyma DJ. The uses of evolutionary biology. Science. 1995;267:41-2.

Gregory TR, Ellis CAJ. Conceptions of evolution among science graduate students. Bioscience. 2009;59(9):792-9. doi:10.1525/bio.2009.59.9.10.

Glaze AL, Goldston MJ. US science teaching and learning of evolution: a critical review of the literature 2000-2014. Sci Educ. 2015;99(3):500-18.

Ha M, Haury DL, Nehm RH. Feeling of certainty: uncovering a missing link between knowledge and acceptance of evolution. J Res Sci Teach. 2012:49(1):95-121. doi:10.1002/tea.20449.

Hill JP. Rejecting evolution: the role of religion, education, and social networks. J Sci Study Relig. 2014;53(3):575-94.

Hermann RS. Cognitive apartheid: on the manner in which high school students understand evolution without believing in evolution. Evol Educ Outreach. 2012;5(4):619-28. doi:10.1007/s12052-012-0446-6.

Ingram EL, Nelson CE. Relationship between achievement and students' acceptance of evolution or creation in an upper-level evolution course. J Res Sci Teach. 2006;43(1):7-24. doi:10.1002/tea.20093.

Johnson RL, Morgan GB. Survey scales: a guide to development, analysis, and reporting. New York: The Guildford Press; 2016.

Jenkins KP, Antolin MF. Evolution and medicine. Evol Educ Outreach. 2011;4(4):556-8. doi:10.1007/s12052-011-0375-9.

Kahan DM. Climate-science communication and the measurement problem. Political Psychol. 2015;36:1-43. doi:10.1111/pops.12244.

Kelemen D. Teleological minds: how natural intuitions about agency and purpose influence learning about evolution. In: Rosengren KS, Brem SK, Evans EM, Sinatra GM, editors. Evolution challenges: integrating research and practice in teaching and learning about evolution. New York: OUP; 2012. p. 66-92.

Labov JB. Evolutionary medicine and the medical school curriculum: meet ing students along their paths to medical school. Evol Educ Outreach. 2011:4(4):561-6. doi:10.1007/s12052-011-0367-9.

Lawson AE, Worsnop WA. Learning about evolution and rejecting a belief in special creation: effects of reflective reasoning skill, prior knowledge, prior belief and religious commitment. J Res Sci Teach. 1992;29(2):143-66. doi:10.1002/tea.3660290205.

Lewandowsky S, Oberauer K. Motivated rejection of science. Curr Dir Psychol Sci. 2016;25(4):217-22. doi:10.1177/0963721416654436.

Mayr $E$. The growth of biological thought: diversity, evolution and inheritance. Cambridge: Harvard University Press; 1982

Meikle WE, Scott EC. Evolutionary medicine: a key to introducing evolution Evol Educ Outreach. 2011;4(4):644-7. doi:10.1007/s12052-011-0379-5.

Nadelson LS, Southerland SA. Development and preliminary evaluation of the measure of understanding of macroevolution: introducing the MUM. J Exp Educ. 2009;78(2):151-90. doi:10.1080/00220970903292983.

Nehm RH, Kim SY, Sheppard K. Academic preparation in biology and advocacy for teaching evolution: biology versus non-biology teachers. Sci Educ. 2009;93(6):1122-46. doi:10.1002/sce.20340.
Nehm RH, Reilly L. Biology majors'knowledge and misconceptions of natural selection. Bioscience. 2007;57(3):263-72. doi:10.1641/B570311.

Nesse RM, Bergstrom CT, Ellison PT, Flier JS, Gluckman P, Govindaraju DR, Niethammer D, Omenn GS, Perlman RL, Schwartz MD, Thomas MG, Stearns SC, Valle D. Evolution in health and medicine Sackler colloquium: making evolutionary biology a basic science for medicine. Proc Natl Acad Sci USA. 2010;107(Suppl 1):1800-7. doi:10.1073/pnas.0906224106.

Newport F. In U.S., 42\% believe creationist view of human origins. 2014. http:// www.gallup.com/poll/170822/believe-creationist-view-human-origins. aspx. Accessed 13 Mar 2015.

O'Brien DT, Wilson DS, Hawley PH. "Evolution for Everyone": a course that expands evolutionary theory beyond the biological sciences. Evol Educ Outreach. 2009;2(3):445-57. doi:10.1007/s12052-009-0161-0.

Rice JW, Olson JK, Colbert JT. University evolution education: the effect of evolution instruction on biology majors' content knowledge, attitude toward evolution, and theistic position. Evol Educ Outreach. 2011;4(1):137-44.

Rutledge ML, Warden MA. The development and validation of the measure of acceptance of the theory of evolution instrument. School Sci Math. 1999;99(1):13-8.

Short SD, Hawley PH. The effects of evolution education: examining attitudes toward and knowledge of evolution in college courses. Evol Psychol. 2015:13(1):147470491501300105.

Sinatra GM, Southerland SA, McConaughy F, Demastes JW. Intentions and beliefs in students' understanding and acceptance of biological evolution. J Res Sci Teach. 2003;40(5):510-28. doi:10.1002/tea.10087.

Smith MU. Current status of research in teaching and learning evolution: I. Philosophical/epistemological issues. Sci Educ. 2009;19(6-8):523-38. doi:10.1007/s11191-009-9215-5.

Smith MU, Siegel H. Knowing, believing, and understanding: what goals for science education? Sci Educ. 2004;13(6):553-82. doi:10.1023/ B:SCED.0000042848.14208.bf.

Southerland SA, Sinatra GM, Matthews MR. Belief, knowledge, and science education. Educ Psychol Rev. 2001:13(4):325-51. doi:10.102 3/A:1011913813847.

Spiegel A, Evans EM, Frazier BF, Hazel A, Tare M, Gram W, Diamond J. Changing museum visitors' concepts of evolution. Evol Educ Outreach. 2012;5:4361. doi:10.1007/s12052-012-0399-9.

Stearns SC, Nesse RM, Govindaraju DR, Ellison PT. Evolution in health and medicine Sackler colloquium: evolutionary perspectives on health and medicine. Proc Natl Acad Sci USA. 2010;107(Suppl 1):1691-5. doi:10.1073/ pnas.0914475107

Wellman HM, Gelman SA. Knowledge acquisition in foundational domains. In: Damon W, Kuhn D, Siegler R, editors. Handbook of child psychology, Vol. 2: cognition, perception and language. 5th ed. New York: Wiley; 1998. p. 523-74.

\section{Submit your manuscript to a SpringerOpen ${ }^{\circ}$ journal and benefit from:}

- Convenient online submission

- Rigorous peer review

- Open access: articles freely available online

- High visibility within the field

Retaining the copyright to your article

Submit your next manuscript at springeropen.com 